\title{
Transient yellow discoloration of the nails for differential diagnosis with yellow nail syndrome
}

\author{
Anca Chiriac ${ }^{1,2,3}$, Adrian Naznean ${ }^{4}$, Cristian Podoleanu ${ }^{5 *}$ and Simona Stolnicu ${ }^{6}$
}

\begin{abstract}
A differential diagnosis must be made between transient yellow discoloration of the nails and yellow nail syndrome. We highlight some practical aspects of yellow nail discoloration.
\end{abstract}

Keywords: Yellow nail syndrome, Yellow discoloration, Nail

Sir,

We read with great interest the article by Vignes et al. recently published by the journal [1].

We would like to add some practical issues related to differential diagnosis of yellow nail discoloration.

A differential diagnosis must be made between transient yellow discoloration of the nails and yellow nail syndrome.

Yellow discoloration of the nails has been reported as an adverse reaction after some drugs such as: quinaqrine used for cutaneous lupus erythematosus [2], after topical use of 5-fluorouracil for the treatment of nail psoriasis (Fig. 1) [3], temsirolimus [4], or bucillamine for rheumatoid arthritis [5], retinoids [6] (Fig. 2). Furthermore, yellow discoloration of the nails has been described during hemodialysis [7], in patients diagnosed with non-Hodgkin lymphoma [8]. Yellow nails can be also observed in patients diagnosed with diabetes mellitus (Fig. 3a, b) [9], tobacco-associated use (Fig. 4), or after intense use of nail polish remover (Fig. 5). In recent years, skin adverse reactions induced by cetuximab have been lately reported; cetuximab is a monoclonal antibody against epidermal growth factor receptor (EGFR) used in the treatment of colorectal cancer [10]. Recently, yellowish distal discoloration was observed in our department in a 67-year-old female patient treated with cetuximab for colorectal cancer (Fig. 6).

\section{Acknowledgements}

Not applicable.

Funding

None reported.

Availability of data and materials

The datasets used and/or analysed during the current study are available from the corresponding author on reasonable request.

\begin{abstract}
Authors' contributions
AC contributed to the management of the patients, the conception of the work and the analysis of data. AN drafted the work, contributed to the proofreading and revising the manuscript. CP contributed to the management of the patients and has been involved in revising the manuscript critically for important intellectual content. SS contributed to the conception of the work and gave final approval of the version to be published. All Authors read and approved the final manuscript.
\end{abstract}

\section{Ethics approval and consent to participate}

All the patients consented to the publishing of the photos containing nonidentifiable images.

\section{Consent for publication \\ All the patients consented to the publishing of the photos containing non- identifiable images.}

\section{Competing interests}

The authors declare that they have no competing interests.

\footnotetext{
* Correspondence: podoleanu@me.com

${ }^{5}$ Department of Internal Medicine, University of Medicine and Pharmacy of Tirgu Mures, 38 Gheorghe Marinescu Street, 540139 Tirgu Mures, Romania Full list of author information is available at the end of the article
} 


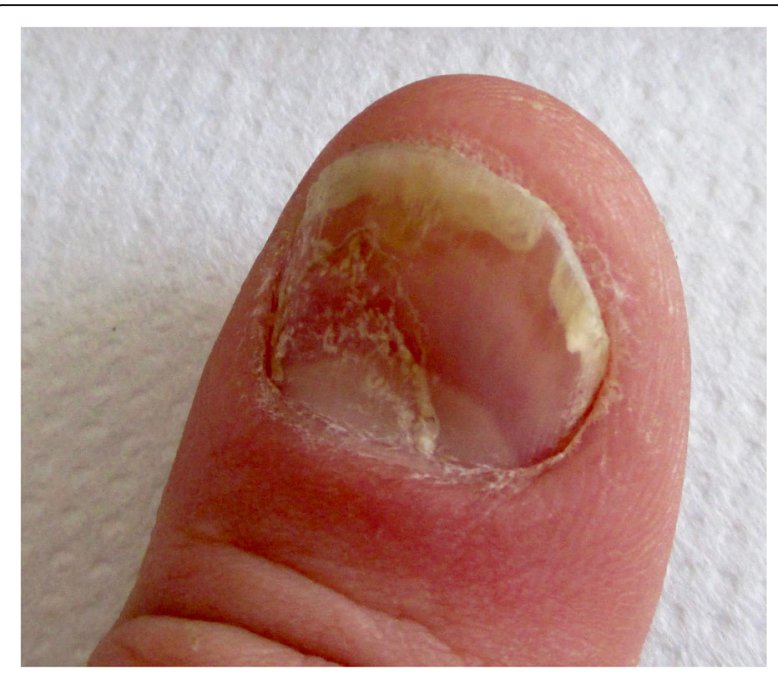

Fig. 1 Diffuse yellow discoloration of the nail plate in a case of nail psoriasis treated with topical 5-fluorouracil (close view)

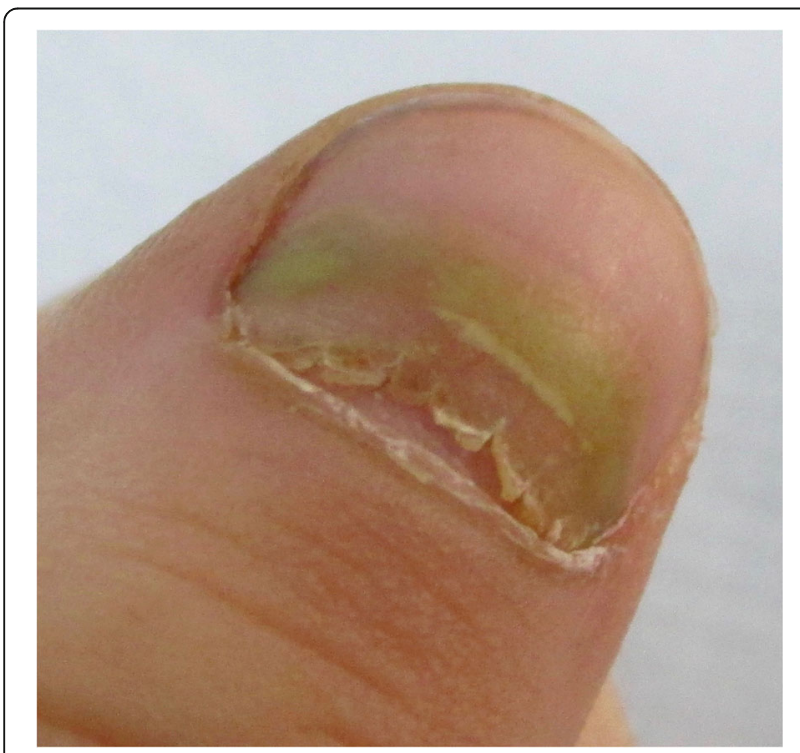

Fig. 2 Yellowish discoloration of finger nails in a teenager while treated with systemic isotretinoin for acne

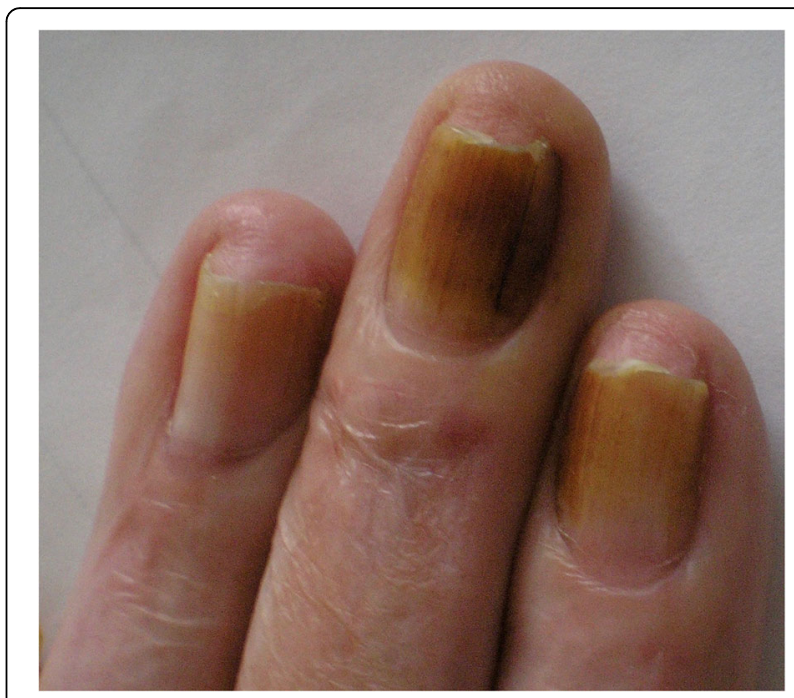

Fig. 4 Tobacco associated yellow nails

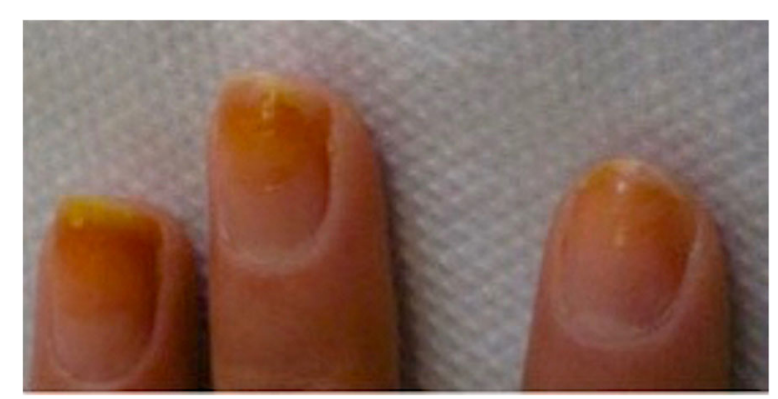

Fig. 5 Transient yellow discoloration as a result of nail polish remover (acetone)
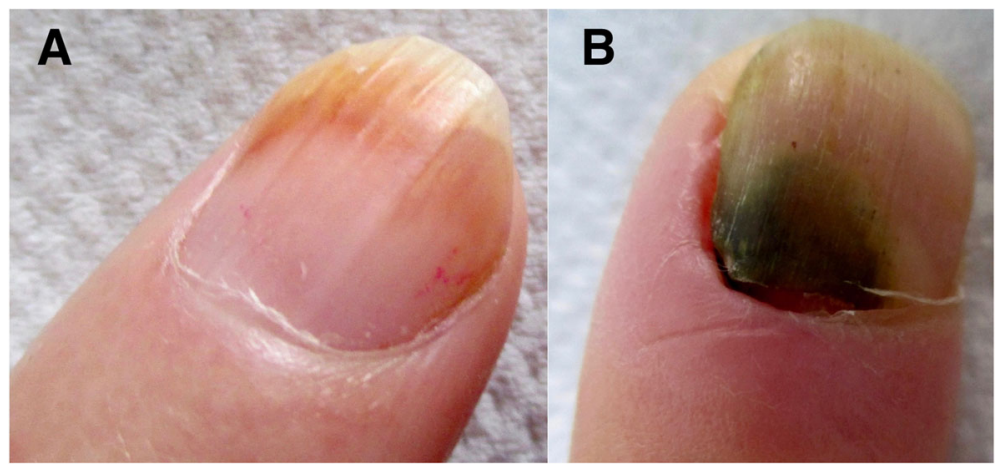

Fig. 3 "Diabetic yellow nails" (a) and yellow-green discoloration of a nail in a diabetic patient due to Pseudomonas aeruginosa infection (b) 


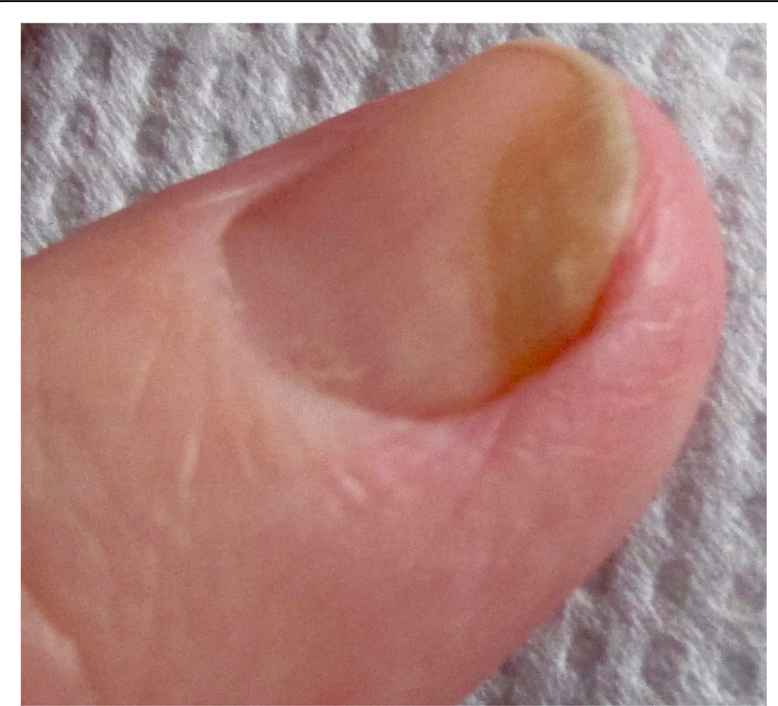

Fig. 6 Distal yellowish discoloration of the nail during treatment with cetuximab

\section{Publisher's Note}

Springer Nature remains neutral with regard to jurisdictional claims in published maps and institutional affiliations.

\section{Author details}

${ }^{1}$ Department of Dermatology, Nicolina Medical Center, lasi, Romania. ${ }^{2}$ Department of Dermato-Physiology, Apollonia University lasi, lasi, Romania. 3"P.Poni" Research Institute, Romanian Academy, București, Romania. ${ }^{4}$ Department of Foreign Languages, University of Medicine and Pharmacy of Tirgu Mures, Tirgu Mures, Romania. ${ }^{5}$ Department of Internal Medicine, University of Medicine and Pharmacy of Tirgu Mures, 38 Gheorghe Marinescu Street, 540139 Tirgu Mures, Romania. ${ }^{6}$ Department of Pathology, University of Medicine and Pharmacy of Tirgu Mures, Tirgu Mures, Romania.

Received: 28 June 2017 Accepted: 24 September 2017

\section{Published online: 02 October 2017}

\section{References}

1. Vignes S, Baran R. Yellow nail syndrome: a review. Orphanet J Rare Dis. 2017;12(1):42

2. Vidal D, Altés J, Smandia JA. Yellow skin discoloration induced by quinacrine in a patient with cutaneous lupus erythematosus. ActasDermosifiliogr. 2013;104(1):89-90.

3. FialloP.Yellow nails as an adverse reaction to the topical use of 5 -fluorouracil for the treatment of nail psoriasis. J Dermatolog Treat 2009; 20(5):299-301.

4. Peuvrel L, Quéreux G, Brocard A, Saint-Jean M, Dréno B. Onychopathy induced by temsirolimus, a mammalian target of rapamycininhibitor. Dermatology. 2012;224(3):204-8.

5. Yamamoto T. YokozekiH.Yellow nails under bucillamine therapy for rheumatoid arthritis: a report of two cases. Rheumatol Int. 2007;27(6):603-4.

6. Li W, Liu Y. QuanLuo, Xue-Mei Li, Xi-Bao Zhang: Off-label uses of retinoids in dermatology. Our Dermatol Online. 2012;3(Suppl 1):259-78.

7. Chiew YW, Peng SJ, Yang CS. Yellowish discoloration of dialyzer. Hemodial Int. 2012;16(3):444-6.

8. Saif M, Jowitt S. Yellow nails in non-Hodgkin lymphoma. Br J Haematol. 2007;136(3):352.

9. Huntley AC. The Skin and Diabetes Mellitus. Photoessay and Review. Dermatology Online Journal. 1995;1 (2):1087-2108.

10. Pinto C, Barone CA, Girolomoni G, Russi EG, Merlano MC, Ferrari D, Maiello E. Management of Skin Reactions During Cetuximab Treatment in Association With Chemotherapy or Radiotherapy: Update of the Italian Expert Recommendations. Am J ClinOncol. 2016;39(4):407-15.

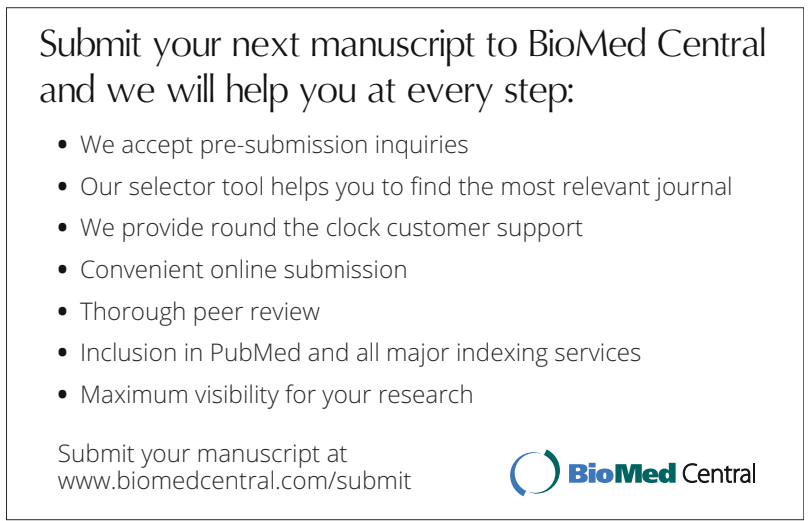

